\title{
Aristóteles, inesse, Leibniz
}

\author{
Vivianne de Castilho Moreira \\ vivicmor@gmail.com \\ Universidade Federal do Paraná, Curitiba, Brasil
}

resumo Em diversas ocasiões, Leibniz recorre à autoridade de Aristóteles a fim de roborar sua tese da verdade como inerência do predicado ao sujeito da proposição. Não é, contudo, evidente em que medida a filosofia aristotélica poderia oferecer amparo a essa reivindicação. Afinal, a Aristóteles tradicionalmente se atribui uma concepção de verdade diferente, consistente em uma relação de correspondência entre a proposição e a realidade que ela se destina a descrever. Sem discutir a conhecida tese da verdade como correspondência, este trabalho é dedicado a investigar em que medida os escritos de Aristóteles permitem que Leibniz respalde neles as suas afirmações. Para tanto, a presente investigação estará focada nos Primeiros e os Segundos Analíticos, obras em que Aristóteles expõe sua teoria do raciocínio e da demonstração. Visa-se averiguar se, e sob que condições, a noção de inerência ali mobilizada pode ser assimilada à noção leibniziana de inerência.

palavras-chave Leibniz; Aristóteles; inerência; demonstração; verdade; proposição

Em seu livro ${ }^{1}$ La Doctrine Leibnizienne de la Vérité, J.-B. Rauzy se surpreende ao observar que os apelos à autoridade de Aristóteles feitos por Leibniz, no intuito de firmar sua concepção intensional de verdade ${ }^{2}$, tenham recebido pouca atenção por parte dos estudiosos. Afinal, não é evidente - ao contrário, antes parece paradoxal - que a caracterização proposta por Leibniz para verdade, como inerência do predicado ao sujeito da proposição, possa amparar-se ou identificar-se à concepção que 
geralmente se atribui a Aristóteles, consoante a qual a verdade de uma proposição estaria assentada em sua correspondência com a realidade sua adaequatio rei. Segundo Rauzy,

Quaisquer que sejam as nuances que se possa reclamar sobre esse ponto e as divergências que podem vir à luz na avaliação do grau de novidade da doutrina, dificilmente se poderia ver nesta uma defesa da verdadecoerência e conjuntamente reconhecer que a doutrina proposta é invariavelmente situada sob a égide de Aristóteles, uma vez que essa égide constitui, ainda hoje, uma das marcas mais seguras do programa correspondentista. É assaz surpreendente constatar quão pouco a crítica se inquietou com essa contradição (RAUZY, 2001, p. 43). ${ }^{3}$

A atribuição da acepção correspondentista de verdade a Aristóteles é em geral corroborada pelas caracterizações de verdadeiro e de falso que encontramos na Metafísica. Aí Aristóteles afirma que:

[...] dizer que não é o que é ou que é o que não é, é falso, ao passo que dizer que é o que é e que não é o que não é, é verdadeiro (ARISTÓTELES, 1997, IV, 5, 1011b26-27). ${ }^{4}$

$\mathrm{Na}$ tentativa de acomodar essa caracterização às afirmações de Leibniz, G. Parkinson sugere que a remissão a Aristóteles possa ser explicada pela consideração da acepção de proposição que, de acordo com ele, seria pressuposta por Leibniz. Parkinson sustenta que, segundo Leibniz, "afirmar uma proposição é afirmar que o conceito do predicado está incluído naquele do sujeito" (PARKINSON, 1965, III, 3, p. 68), o que significaria que a própria forma lógica da proposição envolveria a afirmação da continência do predicado pelo sujeito respectivo. Assim, tomando essa concepção de proposição vis-à-vis a caracterização de verdade extraída do trecho da Metafísica acima, seria correto concluir que o que verificaria uma proposição seria a efetiva continência de seu predicado em seu sujeito, visto ser essa continência o que funda as condições de verdade da proposição. A acepção correspondentista estaria assimilada na concepção leibniziana de verdade porque a realidade apta a verificar uma proposição se esgotaria na própria coerência dos termos articulados nela. Diz Parkinson:

Leibniz pode ter pensado ser óbvio (e por isso ele não explicitou) que sempre que se assere uma proposição verdadeira assere-se que o conceito 
do sujeito inclui o do predicado quando o conceito do sujeito de fato inclui aquele do predicado (PARKINSON, 1965, III, 3, p. 68-69).

A saída tentada por Parkinson, contudo, não parece contemplar todos os aspectos das declarações de Leibniz, visto que, nas alusões a Aristóteles, é à noção de inerência, antes que à de correspondência, que Leibniz se reporta. Não se trataria, aos olhos de Leibniz, de moldar sua concepção de verdade à acepção correspondentista, mas de identificar na herança estagirita a fonte da tese da inerência. Em suas Notationes Generales, Leibniz afirma:

Uma proposição simples é verdadeira se o predicado está contido no sujeito, isto é, se, uma vez resolvidos os termos $A$ e $B$ (o que se faz substituindoos por outros termos equipolentes mais distintos), aparece o valor, isto é, que o conceito do predicado está contido no conceito do sujeito. Eis porque Aristóteles costuma afirmar que o predicado inere ao sujeito ${ }^{5}$.

Atento a esse aspecto da questão, J.-B. Rauzy sugere que a conciliação com a teoria aristotélica se estabeleceria não tanto pela acomodação da tese da verdade como inerência à letra da caracterização correspondentista, mas, antes, pela convicção de que a formulação praedicatum inest subjecto (Cf. LEIBNIZ, 1996, II, p. 43. Phil VII, C, 62 verso; LEIBNIZ, 1988, p. 402; LEIBNIZ, 1996, p. 43) refletiria as condições sob as quais a adaequatio resultaria fundamentada. Segundo ele, sem abrir mão da concepção correspondentista de verdade, Leibniz veria na caracterização intensional a descrição das condições lógicas com base nas quais a correspondência da proposição verdadeira à realidade por ela expressa se evidenciaria:

A relação conceitual - que se trate de uma inerência ou de uma relação mais forte como a identidade - não foi tematizada visando substituir a adaequatio rei, mas, antes, para fundá-la. Eis porque Leibniz pôde, de uma só vez, defender uma definição original de verdade e considerar que essa definição se inscrevia perfeitamente no respeito da tradição mais ortodoxa (RAUZY, 2001, p. 43).

A saída proposta por Rauzy, embora resguarde a especificidade própria de cada uma das concepções de verdade contrastadas, também se afigura parcial. Como o próprio autor sublinha, ela não elimina uma dificuldade, que diz respeito ao teor da herança que Leibniz declara dever a Aristóteles. 
Afinal, como já observado, é sobretudo a tese da inerência, antes que a concepção de verdade como correspondência, que Leibniz pretende compartilhada com Aristóteles. No entanto, permanece duvidoso que essa tese tenha sua raiz no pensamento aristotélico. A esse respeito Rauzy pondera:

A referência a Aristóteles em matéria de inclusão conceitual apoia-se sempre exclusivamente sobre um argumento terminológico tomado de empréstimo do vocabulário da silogística. Quando formula um silogismo com letras, Aristóteles sempre coloca o predicado e o sujeito na primeira

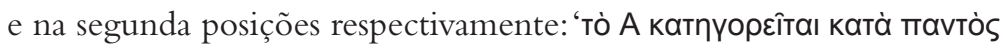

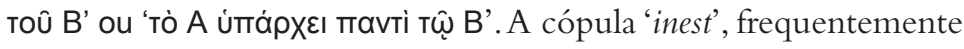
empregada no Aristoteles latinus, traduz o grego 'úmápxeı' tal como empregado nos Analíticos. É verdade que essa maneira de traduzir aproxima a predicação da esfera de uma pertinência ou de uma inclusão. Esse argumento permanece, todavia, insuficiente para justificar por si o projeto de um cálculo intensional fundado sobre a subjectio. (RAUZY, 2001, p. 173)

É para essa dificuldade que o presente trabalho está voltado. Assumindo, a título de hipótese, que Leibniz teria razões para amparar-se em Aristóteles com vista a sustentar sua tese da verdade como inerência, investigaremos aqui o que poderia estar na base daquelas razões. Antes, contudo, de iniciar a investigação, é importante sublinhar que, tendo em vista o objetivo proposto aqui, que restringe-se a buscar no pensamento de Aristóteles respaldo para as afirmações de Leibniz a respeito da eventual origem aristotélica da tese do praedicatum inest subjecto, não será abordada a questão concernente à relação entre as duas acepções de verdade, a saber, a intensional, por um lado, e a correspondentista, por outro. Mesmo encontrando na filosofia de Aristóteles amparo para as afirmações de Leibniz, passaremos ao largo da questão que imediatamente se ergue, concernente à conciliação das duas concepções de verdade.

\section{II}

Conforme observa Rauzy, o verbo inesse, aqui traduzido por inerir, corresponde ao termo reservado pelos escolásticos à tradução do grego úmápxદıv 
(Cf. RAUZY, 2001, p. 173; Fichant, M. in: LEIBNIZ, 2004, p. 441, n.40), que Aristóteles emprega em seus Primeiros Analíticos para designar em linguagem perspícua a relação entre o predicado e o sujeito em uma proposição ${ }^{6}$. Assim, uma proposição categórica que habitualmente se representa pela fórmula Todo [algum] [nenhum] $S$ é [não é] $P$ ganha, nos Primeiros Analíticos, a seguinte formulação: P inere [não inere] a todo [algum] [nenhum] $S$ (ARISTÓTELES, 1989, I 1, 24a16-20). Por seu turno, a proposição ou, se preferirmos, premissa <ாро́табıৎ> - é definida como "um discurso $<$ 'óyos> que afirma ou nega algo a respeito de algo" (ARISTÓTELES, 1989, I 1, 24a16-17). ${ }^{7}$

Convém sublinhar que Aristóteles estende esse uso do verbo inerir <úmápxદıv> a qualquer que seja a forma de atribuição em uma proposição categórica, pouco importando se o predicado atribuído é assumido um predicado essencial ou acidental. De acordo com ele, "de tantas maneiras quantas se diz ser ou é verdadeiro dizer, dessas tantas maneiras também é preciso considerar que inerir significa" (ARISTÓTELES, 1989, I 36, 48b2-4). ${ }^{8}$ Não se deve, em virtude disso, assimilar o verbo inerir a um apenas dos termos da distinção, traçada no início do opúsculo sobre

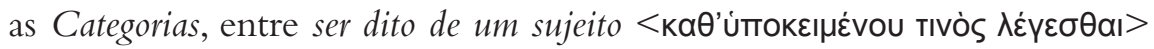

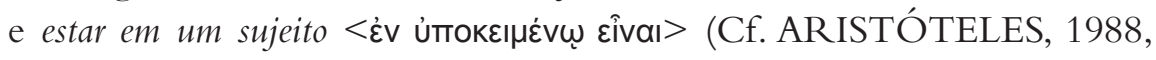
1a20-b9). Na medida em que tanto ao que é dito de um sujeito quanto ao que está em um sujeito se aplica, em alguma medida, o verbo ser $<$ हîvaı $>$ ", nesta mesma medida a ambos convém também o verbo inerir.

Os itens afirmados ou negados na proposição, bem como aqueles a respeito dos quais nela se afirma ou nega algo, são os termos, definidos como "aquilo em que se resolve uma proposição, como o predicado e aquilo de que se predica, uma vez eliminado o ser ou o não ser" ${ }^{10}$. Por fim, assim como a proposição consiste em um discurso que se constitui a partir de uma articulação de termos de certa forma, também o silogismo é um discurso consistente em uma articulação de proposições segundo certa forma. Uma articulação de proposições formará um silogismo se as proposições se dispuserem de tal maneira que, certas dentre elas sendo postas, a restante necessariamente decorre de terem aquelas sido postas. Diz Aristóteles:

O silogismo é um discurso < < ́óyos $>$ no qual, uma vez postos certos [itens], algo diferente do que foi posto necessariamente se segue em virtude disso (ARISTÓTELES, 1989, I 1, 24b18-20). ${ }^{11}$ 
Estamos aqui, portanto, às voltas com o domínio do discurso $<\lambda$ óyo $>$, mais precisamente, de um tipo específico de discurso: o discurso por meio do qual silogizamos ou raciocinamos ${ }^{12}$. As condições mínimas para que um silogismo se efetue, de acordo com Aristóteles, reúnem-se em três termos, dispostos de certa forma em duas proposições (Cf.ARISTÓTELES, 1989, I 25). Um dentre esses termos se repetindo em ambas - as premissas -, a depender da forma consoante a qual esse termo se articular com cada um dos demais em cada proposição, um silogismo pode se efetuar, conduzindo a uma terceira proposição - a conclusão do silogismo - na qual se articulam os dois termos que não se repetem nas premissas - os extremos $<$ тò äkpa $>$. A articulação na conclusão corresponde ao resultado do cômputo efetuado a partir da forma de articulação dos termos nas premissas. Esse cômputo está fundado na aptidão do termo que se repete nas premissas para transferir, por assim dizer, a relação de inerência constitutiva das proposições que figuram como premissas. Essa aptidão, por seu turno, depende do modo como os termos estão dispostos nelas.

Isso se ilustra por um exemplo de silogismo aristotélico. Tomemos aqui o conhecido Barbara, que, como nos é bem familiar, veicula que, se $A$ inere a todo $B$ e $B$ inere a todo $C$, então $A$ inere a todo $C$. É fácil ver que o êxito do silogismo depende da maneira como os termos se articulam nas duas proposições: a quantidade e a qualidade destas, combinadas com o modo consoante o qual os termos estão distribuídos nos papéis de sujeito e de predicado em cada qual. Se, por exemplo, a primeira proposição fosse invertida, isto é, se, ao invés de termos $A$ inere a todo $B$, tivéssemos $B$ inere a todo $A$ ou, ainda, $A$ inere a algum $B$, nenhum resultado decorreria do par formado, visto ser esse par compatível com diversas articulações possíveis entre $A$ e $C^{13}$. Ainda, se, ao invés de $B$ inere a todo $C$, tivéssemos $B$ inere a nenhum $C$, igualmente várias combinações possíveis entre $A$ e $C$ seriam admitidas compatíveis com o par $A$ inere a todo $B$ e $B$ inere a nenhum $C$. Por fim, se nenhum termo se repetisse, mas tivéssemos dois pares de termos distribuídos nas duas proposições, por exemplo, $A$ inere a todo $B$ e $D$ inere a todo $C$, como quer que os termos estivessem distribuídos, e quaisquer que fossem a quantidade e a qualidade das proposições, seria impossível efetuar um silogismo. Pois qualquer que fosse a combinação dos quatro termos nas duas premissas, nada necessário decorreria com respeito aos termos não articulados nelas ${ }^{14}$. É condição sine qua non para o silogismo 
a repetição de um termo nas premissas, repetição na qual se funda a articulação veiculada na conclusão (Cf. ARISTÓTELES, 1989, I 23, 11-13). Seria quiçá esse papel mediador desempenhado pelo termo que se repete que inspiraria o nome " $\mu \dot{\sigma} \sigma o v "$, médio, para esse termo. ${ }^{15}$ Não por acaso, Aristóteles sustentará, como exploraremos adiante, ser o termo médio do silogismo a causa <aïtıov> da articulação dos termos na conclusão (Cf. ARISTÓTELES, 1989, Segundos Analíticos II 2, 90a6-7).

\section{III}

Assim sumariamente exposta a estrutura do discurso silogístico, abordemos um tipo específico de discurso silogístico segundo Aristóteles, a saber, o discurso científico. Este discurso expressa o conhecimento científico, que consiste no conhecimento "[d]a causa (...) pela qual o fato é, que ela é sua causa e que não é possível ser de outro modo" (ARISTÓTELES, 1989, Segundos Analíticos, I, 2, 71b10-12). A razão subjacente a essa concepção de conhecimento científico pode ser extraída da resposta que Aristóteles oferece para a questão concernente à possibilidade de um conhecimento universal, isto é, de um conhecimento que assegura a certeza da validade universal da proposição conhecida. De acordo com ele, um conhecimento dessa envergadura não pode estar fundado no percurso exaustivo da totalidade das instâncias subsumidas sob os conceitos articulados na referida proposição, visto que um conhecimento assim não se habilita a fundar aquela certeza. Segundo Aristóteles,

Não se deve falar como alguns que tentam resolver a seguinte dificuldade: em face da pergunta acaso você sabe que toda dupla é par?, a quem responde afirmativamente, é apresentada uma dupla que este não sabia que existia, de modo que não sabia ser par. Eles resolvem dizendo que sabem não que toda dupla é par, mas que são pares aquelas duplas que conhecem. Ora, eles conhecem aquilo de que têm a demonstração e aquilo a respeito do que fazem suas assunções. E fazem assunções não a respeito do que sabem que é triângulo ou número, mas absolutamente $<\dot{\alpha} \pi \lambda \hat{\omega} \varsigma>$ a respeito de todo triângulo ou de todo número (ARISTÓTELES, 1989, I, 1, 71a30-b3). ${ }^{16}$ 


\section{4}

A solução proposta por Aristóteles para a dificuldade consiste, como ficará claro sobretudo nos dez primeiros capítulos de Segundos Analíticos I, em fazer recair a certeza quanto à validade universal de uma proposição no conhecimento das relações entre as definições dos nomes que ocupam os lugares dos termos nessa proposição ${ }^{17}$. No caso do exemplo, conhece-se universalmente que toda dupla é par quando se conhece o nome que, sendo corretamente predicado por si mesmo de dupla - o que aqui significa que esse nome integra a definição de dupla (Cf. ARISTÓTELES, 1980, I, 4, 73a34-b3) -, por outro lado, encerra em sua definição o termo par, permitindo, nesta medida, tornar evidente a verdade da atribuição de par a dupla. Em uma formulação de inspiração leibniziana, poderíamos dizer que, de acordo com Aristóteles, conhece-se universalmente que toda dupla é par quando se conhece, na definição de dupla, o predicado que encerra o termo par, e que permite, nesta medida, evidenciar que par inere à noção de dupla ${ }^{18}$.

Para Aristóteles, portanto, o conhecimento pela causa proporciona a certeza quanto à correção de certa crença. Ele diz respeito, nesta medida, às condições epistêmicas sob as quais se pode assegurar a certeza da verdade de uma proposição. Isso evidentemente presume já dada previamente certa acepção de verdade, que, contudo, não está explicitada nos textos examinados. Que acepção seria essa é uma questão que se pode deixar de lado por ora, visto que, como já assinalado, cumpre aqui concentrar a investigação nas razões de Leibniz para se remeter à filosofia de Aristóteles com o intuito de justificar sua acepção intensional de verdade. Desse ponto de vista, examinar a própria concepção aristotélica de verdade, antes que as teses que, na filosofia aristotélica, poderiam satisfazer os propósitos de Leibniz, não teria outro efeito que nos desviar do objetivo visado aqui. Centremos, pois, nossa atenção nas convicções de Aristóteles a respeito do lugar que ocupam as relações intensionais entre os termos em uma proposição verdadeira. Como já visto, estas dizem respeito sobretudo às condições de certeza da verdade.

Essas condições de certeza se deixam estruturar silogisticamente com os termos dupla e par no papel de extremos que se articulam na conclusão, cada qual articulando-se, em uma das premissas, com o termo que inere a dupla e ao qual par inere ${ }^{19}$. Tal termo figuraria, eo ipso, como o termo médio do silogismo em tela. A um silogismo dessa natureza - que, por 
estar fundado nas relações intensionais entre os nomes, é apto a garantir certeza própria do conhecimento científico - Aristóteles reserva o nome

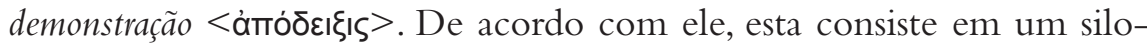
gismo cujas premissas são verdades que encerram as causas da conclusão

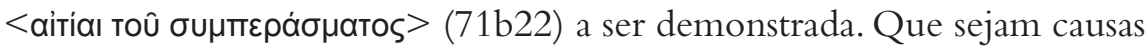
da conclusão se compreende a partir da própria definição de conhecimento científico: se este consiste no conhecimento causal do conhecido; se, além disso, o conhecimento científico se obtém por meio da demonstração, sendo, nesta medida, o conhecimento daquilo que a demonstração proporciona, que é expresso na conclusão desta; segue-se que o conhecimento científico corresponde ao conhecimento causal do que é expresso em uma conclusão de uma demonstração. Ora, se tal conhecimento se obtém a partir das premissas e com base nelas, serão elas, eo ipso, as causas da conclusão. Diz Aristóteles:

Chamo de demonstração o silogismo científico. E chamo de científico aquele que, porque o possuímos, conhecemos cientificamente.

Se, então, conhecer cientificamente é tal como estabelecemos, é necessário também que a ciência demonstrativa se efetue a partir de itens verdadeiros, primeiros imediatos, mais cognoscíveis, anteriores e causas da conclusão. E assim também serão os princípios adequados ao demonstrado. Sem isso, haverá silogismo, mas não demonstração (ARISTÓTELES, 1980, 71b17-24). ${ }^{20}$

Claro está que a noção aristotélica de causa não deve ser confundida com o que ficará posteriormente restrito à causalidade eficiente, e que se entende como o que, estando em uma certa relação de fundamento e consequência com um efeito, produz este último. Nos Segundos Analíticos, Aristóteles emprega a noção de causa sob uma acepção diversa, para designar a explicação relevante para uma proposição verdadeira, ou o que encerra as razões para sua verdade ${ }^{21}$ (ARISTÓTELES, 1980, II, 11, 94a20-95a9). De acordo com ele, nem toda explicação para algo consistirá em uma explicação causal. Esta última deve encerrar uma anterioridade lógica, antes que meramente epistêmica ou psicológica, em relação àquilo que é destinada a explicar, como ficará claro em Segundos Analíticos I 13, a partir da distinção traçada por Aristóteles entre os silogismos do

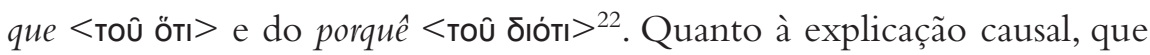


proporciona a ciência, a causa se descortina nas próprias definições dos nomes figurando nas proposições.

\section{IV}

O exposto acima apresenta sumariamente os requisitos que, de acordo com Aristóteles, o conhecimento demonstrativo deve satisfazer. Como visto, esse conhecimento se estrutura em uma ordem lógica de anterioridade e posterioridade: o que é logicamente anterior e funda o conhecido é também anterior na ordem da demonstração. Está de posse desse tipo de conhecimento, portanto, aquele que conhece as relações intensionais dos termos na proposição conhecida. Em síntese, para Aristóteles, conhecer cientificamente uma proposição como verdadeira implica conhecer que a definição do seu termo sujeito envolve o termo predicado respectivo.

Aristóteles reconhece que, contudo, nem todos os conhecimentos que possuímos observam essa estrutura, visto que, em boa parte das vezes, conhecemos que uma proposição é verdadeira sem conhecermos o termo médio do silogismo que evidencia sua verdade, quer dizer, não conhecemos o porquê - ou a causa - que explica essa verdade. Neste caso, passar do conhecimento do que ao conhecimento do porquê exigirá uma investigação

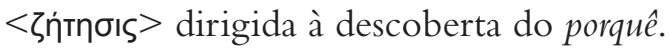

O método a ser observado na investigação será examinado no segundo livro de Segundos Analíticos, à luz dos resultados obtidos no livro precedente, concernentes à ordem do conhecimento demonstrativo. Aristóteles toma como fio condutor o procedimento que constitui a demonstração, amparado na avaliação de que a consideração deste permite determinar o procedimento a ser adotado a fim de se obter o que falta à demonstração.Visto que, conforme examinado acima, quando se conhece que uma proposição é verdadeira sem se conhecer o porquê de sua verdade, se conhece o que pode ser assumido como conclusão de uma demonstração sem, contudo, se conhecer as respectivas premissas; visto, ainda, que o que é articulado na conclusão de uma demonstração - ou, mais geralmente, de um silogismo qualquer - são os termos extremos, que figuram, cada qual, em uma premissa da demonstração ou do silogismo, segue-se que o que em tudo isso resta por conhecer a fim de completar a demonstração não é senão o que 
ocupará a posição de termo médio nas premissas correlativas. Aristóteles daí conclui que, "em todas as investigações, investiga-se ou se há termo médio ou qual é o termo médio. Pois o termo médio é a causa, e é isto que se investiga em todos esses casos" (ARISTÓTELES, 1980, II, 2, 90a5-7). ${ }^{23}$

Aristóteles denomina indução o procedimento destinado a determinar o termo médio de um silogismo. De acordo com ele, determina-se por indução o termo médio de um silogismo a partir do exame de seus termos extremos - mais precisamente, a partir do exame de um dos nomes que figuram na conclusão do referido silogismo:

A indução, isto é, o silogismo indutivo, é o silogizar por meio de um dos extremos que o outro pertence ao termo médio. Como, por exemplo, se da atribuição de $A$ a $C$ o médio for $B$, [a indução consiste em] mostrar por meio de $C$ que $A$ inere a $B$. Pois é assim que efetuamos as induções (ARISTÓTELES, 1989, II, 23, 68b15-18). ${ }^{24}$

A indução constitui-se, assim, no raciocínio pelo qual se descobre as premissas do silogismo apto a provar certa proposição reconhecida como verdadeira. Pois, segundo Aristóteles, daquilo para o que se dispõe de um termo médio, o silogismo se faz por meio do termo médio. Mas daquilo de que não se dispõe, o silogismo se faz por indução (Cf.ARISTÓTELES, 1989, II, 23, 68b31-32). A indução, portanto, como ele próprio sublinha, é, de certa maneira, um raciocínio inverso ao silogismo. Pois o silogismo "mostra que o extremo inere ao terceiro por meio do médio. Já a indução mostra que o extremo inere ao médio por meio do terceiro" (ARISTÓTELES, 1989, 68b33-35). ${ }^{25}$

Essa contraposição entre indução e silogismo assegura à primeira um alcance bem mais amplo do que o mero domínio da investigação <לn்тn$\sigma \varsigma^{>}>$visando determinar o termo médio de uma demonstração. Afinal, assim como a demonstração consiste em apenas uma espécie de silogismo ${ }^{26}$, assim também a indução adequada à investigação científica corresponde a apenas um tipo específico de indução ${ }^{27}$.Visto, contudo, que estamos aqui às voltas com o que é próprio do conhecimento pela causa, restrinjamos nossa consideração ao tipo de indução adequado ao que corresponde, aos olhos de Aristóteles, à explicação causal.

Como já avançado, de acordo com ele, cabe a essa explicação assegurar a certeza quanto à validade universal de certa relação entre os itens que 
comparecem como termos em uma proposição - o sujeito e o predicado. Como também já avançado, para ele, tal certeza é assegurada pelo conhecimento de um nexo fundado nas definições daqueles itens, ou, para empregar suas próprias palavras, ao que inere a esses itens por si mesmos. Diz Aristóteles:

Chamo universal o que inere a todo, por si mesmo e enquanto tal. É evidente, portanto, que o que é universal inere necessariamente ao fato. $\mathrm{O}$ por si mesmo e o enquanto tal são o mesmo, por exemplo, à linha enquanto tal inere o ponto e a reta (pois estes lhe inerem enquanto linha) e ao triângulo enquanto triângulo inere ter a soma dos ângulos internos igual a dois ângulos retos, pois o triângulo por si mesmo equivale a dois ângulos retos (ARISTÓTELES, 1980, Segundos Analíticos I, 4, 73b26-32). ${ }^{28}$

No que tange à expressão por si mesmo, será relevante considerar aqui duas acepções sob as quais Aristóteles a emprega ${ }^{29}$. Sob uma primeira acepção, já mencionada anteriormente, um certo predicado $P$ inere por si mesmo a um sujeito $S$ se e somente se $P$ integra a definição de $S$. Em uma segunda acepção, reversa à anterior, um certo predicado $P$ inere por si mesmo a um sujeito $S$ se e somente se $S$ integra a definição de $P$, de tal sorte que $P$ unicamente se atribui ao que é $S$. Em qualquer das acepções, um predicado inere por si mesmo a um sujeito se, e somente se, alguma relação de inerência vige entre um deles e a definição do outro ${ }^{30}$.

Por conseguinte, o caráter universal que assegura o conhecimento causal, segundo Aristóteles, requer o inerir por si mesmo, que, por seu turno, funda-se nas definições dos termos a respeito dos quais versa a demonstração. Aristóteles conclui:

Portanto, se a ciência demonstrativa é a partir de princípios necessários (pois o que é cientificamente conhecido não é possível ser de outro modo), e se são necessários aos fatos os que lhes inerem por si mesmos (pois, destes, uns inerem ao o que é, e os outros, lhes inerem ao o que é aqueles de que eles são predicados [...]), é evidente que o silogismo demonstrativo será a partir de itens desse tipo." (ARISTÓTELES, 1980, Segundos Analíticos I, 6, 74b5-11) ${ }^{31}$

É fácil concluir a esta altura que a indução voltada para a explicação causal de uma proposição verdadeira $P$ inere a $S$ demandará o exame do sujeito 
dessa proposição visando nele descobrir, dentre os atributos que lhe inerem por si mesmo, aquele ao qual o referido predicado também inere por si mesmo, pois só assim, como vimos, se obterá a universalidade intrínseca à explicação causal. Apresentada nesses termos, a indução de caráter científico se pautaria pela análise das noções e teria por objetivo alcançar o que Leibniz descreveria como uma demonstração a priori da proposição em tela (Cf. LEBNIZ, 1988, pp. 518-519).

\section{V}

Vemos que o que aos olhos de Leibniz é intrínseco à verdade enquanto tal vige, segundo Aristóteles, para as verdades conhecidas ou cognoscíveis cientificamente. Essa conclusão evidentemente não autoriza a atribuição da tese do praedicatum inest subjecto a Aristóteles, como Leibniz expressamente pretende. Para tanto, faltaria mostrar que, de acordo com o primeiro, as verdades enquanto tais são todas cientificamente cognoscíveis.

Por surpreendente que possa parecer quando leva em conta outras teses que integram o corpus da filosofia aristotélica, é essa tese que Aristóteles parece sustentar em seus Segundos Analíticos ${ }^{32}$. Aí ele afirma que investigar $<$ ¿nteî > se um certo predicado $P$ inere a um sujeito $S$ resulta exatamente o mesmo que investigar se um termo médio qualquer articula um certo predicado $P$ a um sujeito $S$. Segundo ele:

quando investigamos se é em sentido absoluto, ou se é tal, investigamos se um termo médio é [explicação] disso (ARISTÓTELES, 1980, Segundos Analíticos II 2,89b37-38). ${ }^{33}$

Verificar que é ou que é tal é, portanto, verificar que há um termo médio articulando os extremos. Ora, como visto, no contexto dos Segundos

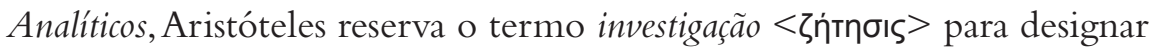
o procedimento de indução próprio da ciência. $\mathrm{Na}$ investigação, não se trata de buscar um termo médio em um silogismo qualquer, mas de buscar o que pode figurar como termo médio em uma demonstração. Nesta medida, a coincidência entre investigar se $S$ é $P$ e investigar se um termo médio explica a inerência de $P$ a $S$ implica que, para toda verdade da forma $S$ é $P$, é legítimo presumir que o predicado inere por si mesmo ao 
sujeito respectivo. Não por acaso Aristóteles prossegue defendendo que o mero conhecimento de que certa proposição é verdadeira basta como justificativa para investigar o porquê de sua verdade, o qual corresponde ao termo médio do silogismo que proporciona sua demonstração. Diz ele:

Uma vez conhecido se é ou que é tal (...), passamos a investigar o porquê ou o o que é, e então investigamos o que é o termo médio (...). Pois o termo médio é a causa e é isso que se investiga em todos esses casos (ARISTÓTELES, 1980, Segundos Analíticos, II, 2, 89b38-90a7). ${ }^{34}$

É importante sublinhar que Aristóteles não restringe o tipo de proposição da forma $S$ é $P$ que tem em mira como conclusão demonstrada àquelas proposições que expressariam predicações essenciais. Ao contrário, ele sustenta que as conclusões das demonstrações consistem em proposições que não veiculam predicações essenciais, mas atribuem aos gêneros que figuram como sujeitos respectivos o que ele denomina "acidentes por si mesmos":

São três os itens nas demonstrações: o primeiro é o demonstrado - a conclusão - e este é o que inere ao gênero por si mesmo; o segundo são os axiomas (são axiomas aqueles a partir dos quais se efetua a demonstração); o terceiro é o gênero sujeito cujas afecções e os acidentes por si mesmos são evidenciados pela demonstração (ARISTÓTELES, 1980, Segundos Analíticos, I, 10, 75a39-b2). ${ }^{35}$

No que tange aos acidentes demonstráveis, a necessidade que a demonstração assegura de que inerem por si mesmos ao sujeito a que se atribuem não acarreta, aos olhos de Aristóteles, que apenas o que se circunscreve no domínio da necessidade lógica seja demonstrável. Se assim fosse, não seria possível conhecer cientificamente o que se passa no mais das vezes mas não exibe a regularidade do que é logicamente necessário, como pretende Aristóteles (Cf. ARISTÓTELES, 1980, Segundos Analíticos, I 30, 87b19-22). ${ }^{36}$

Essas considerações, embora não bastem para assegurar que Aristóteles antecipe a tese do praedicatum inest subjecto nos termos em que Leibniz a concebe, evidenciam que este tem fortes razões para buscar ampará-la sobre a autoridade de Aristóteles. Afinal, é inegável que a filosofia aristotélica está muito mais comprometida com aquela tese do que uma 
inspeção superficial dos escritos de Aristóteles permitiria entrever. Essa conclusão favorece a suspeita de que as eventuais diferenças que se poderia identificar entre as convicções de Leibniz e de Aristóteles no que concerne à noção intensional de verdade bem poderiam dever-se mais a uma convicção quanto à pertinência de se levar às últimas consequências as teses estagiritas do que a uma divergência com respeito a elas.

É claro que colocar essa suspeita à prova requer aprofundar o exame da filosofia de Aristóteles a fim de precisar em que termos, e por que razões, este teria limitado o alcance do conhecimento científico, limitando na mesma medida o alcance do domínio de verdades para as quais estimaria válido pretender que se deixem explicar a partir da análise do termo sujeito respectivo. Esta tarefa, contudo, ultrapassa o escopo do presente trabalho, que restringiu-se a procurar no pensamento aristotélico os subsídios aptos a respaldar a convicção de Leibniz quanto à linhagem peripatética de sua tese do praedicatum inest subjecto. A esse respeito, o exposto acima autoriza concluir que Leibniz não precisa amparar suas afirmações sobre o terreno movediço de uma coincidência terminológica frágil à equivocidade, como teme Rauzy, pois a doutrina aristotélica da ciência proporciona um solo firme e afeito à tese leibniziana da verdade como inerência.

\footnotetext{
${ }^{1}$ Agradeço aos pareceristas deste artigo pela leitura atenta e as sugestões valiosas à sua versão anterior. Agradeço também a Sálvio Nienkötter pelas observações sempre pertinentes a respeito daquela versão.

${ }^{2}$ Ver por exemplo Generales Inquisitiones de Analysi Notionum et Veritatum (doravante: GI), \$16 (AA VI, iv, p. 751).Ver também Primae Veritates,1988, pp. 518-519.

${ }^{3}$ Para uma discussão sobre essa dificuldade, ver PARKINSON, 1965, p. 68 e seg.

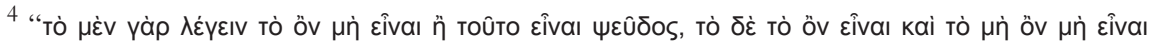

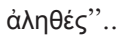

5 “Vera est propositio simplex, si praedicatum in submeto continetur, hoc est si resolutis terminis $A$ et $B$ (quod fit substituendo alhos terminos aequipollentes magis distinctos), apparet valorem sive conceptum praedicati contineri in conceptu subjecti. Unde et Aristoteles dicere solet praedicatum inesse subjecto" (AAVI, iv, p. 551).Ver também OFI, pp. 518-519: "Semper igitur praedicatum seu consequens inest subjecto seu antecedenti. et in hoc ipso consistit natura veritatis in universum seu connexio inter terminos enuntiationis, ut Aristoteles observavit" $<$ Sempre o predicado ou o consequente inere ao sujeito ou ao antecedente, e é precisamente nisso que consiste universalmente a natureza da verdade, quer dizer, a conexão entre os
}

doispontos, Curitiba, São Carlos, vol. 11, n. 2, p.47-67, outubro, 2014 
termos do enunciado, como aliás Aristóteles já havia observado>. E GI \$16 (AAVI, iv, p. 751): "Propositio Affirmativa $A$ est $B$ sive $A$ continet $B$, seu (ut loquitur Aristoteles) ipsi $A$ inest $B$ (in recto scilicet)" <Proposição afirmativa: $A$ é $B$, ou seja, $A$ contém $B$, ou, como diz Aristóteles, $B$ inere a $A$ (diretamente) $>$.

${ }^{6}$ Cf. por exemplo a caracterização de proposição < пाрóтaбıৎ> em Primeiros Analíticos I 1, 24a16-20.Ver a respeito AFRODISIAS, 1883, p. 54, 21-29; e PATZIG, 1968, I \ 4.

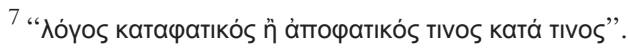

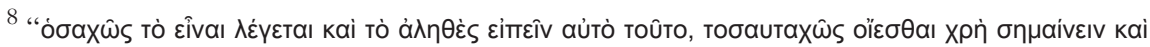
Tò úrrápXeıv".

${ }^{9}$ Segundo Aristóteles, a distinção entre ser dito de um sujeito e estar em um sujeito divide aquilo

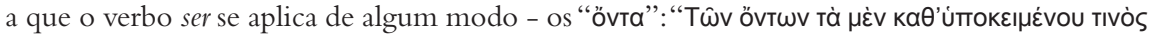

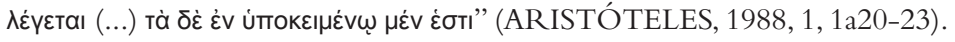

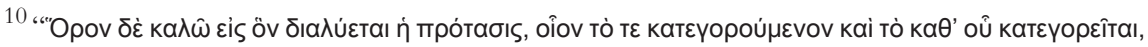

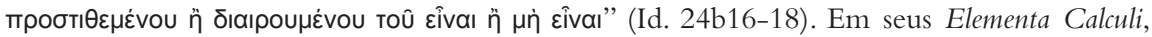
Leibniz adota a mesma caracterização de termo (Cf. Phil V, 8, b, 9 recto - Leibniz, 1988, p. 49. Ver também p. 77: Phil $V, 8, f, 21$ recto).

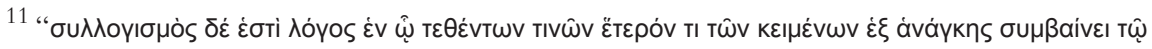
TaûTa हîvaı”.

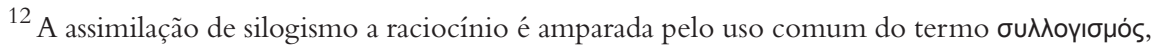
bem como do verbo cognato $\sigma u \lambda \lambda o \gamma i \zeta \varepsilon \sigma \theta a$, entre os antigos. Conforme observa R. Smith, "Aristóteles não pretende definir a palavra sullogismos sob uma acepção estrita como é a de silogismo; tampouco essa palavra foi cunhada por ele próprio. Etimologicamente, um silogismo é o resultado de um ato de 'silogizar' (sullogizesthai). O último verbo é o composto de sun- ('-com') e logizesthai ('calcular'), de modo que o sentido não técnico de sullogizesthai é 'somar' ou 'computar' (um sentido que remonta a Heródoto), e sullogismos é uma 'computação'. Platão usa tanto sullogismos quanto sullogizesthai, algumas vezes em conexão com extrair conclusões em argumentos, mas sempre sob o sentido mais amplo de somar ou calcular"

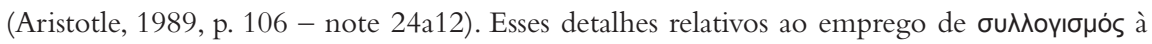
época de Aristóteles não eram desconhecidos pelos contemporâneos de Leibniz. Em seu De Corpore, Hobbes já advertia que aquilo que "adicionamos e subtraímos, isto é, que levamos em

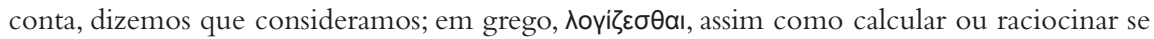

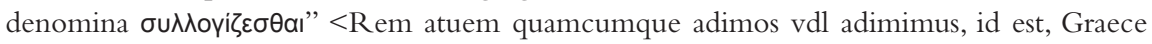

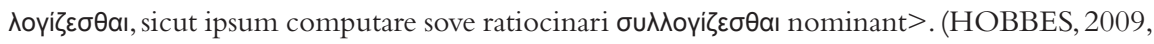
I, 1, $₫ 3$, p. 25 - Opera Latina I, 5 - A3).

${ }^{13}$ Tanto o par $B$ inere a todo $A$ e $B$ inere a todo $C$ quanto o par $A$ inere a algum $B$ e $B$ inere a todo $C$ são compatíveis com as combinações entre $A$ e $C$ seguintes: $A$ inere a todo $C$ e $A$ inere a nenhum C. Na esteira destas, também $\operatorname{com} A$ inere a algum $C \mathrm{e} \operatorname{com} A$ não inere a algum $C$.

${ }^{14}$ Do par acima apresentado a título de ilustração, nada decorre de necessário, seja entre $A$ e $C$, seja entre $A$ e $D$, ou entre $B$ e $C$ ou $B$ e $D$.

${ }^{15}$ Para uma discussão a respeito, ver PATZIG, 1968, III $\$ 14$ e IV, $\-\$ 24$.

doispontos, Curitiba, São Carlos, vol. 11, n. 2, p.47-67, outubro, 2014 


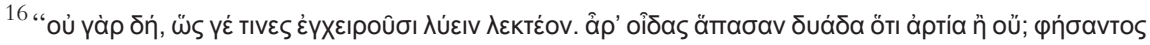

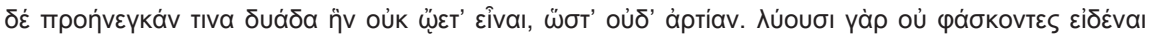

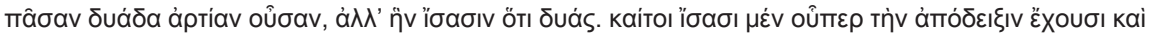

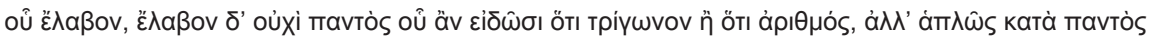

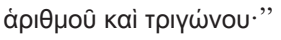

${ }^{17}$ Essa questão será examinada com mais detalhe adiante.

18 De acordo com Leibniz, a análise das noções que conduz à demonstração da proposição reside na substituição reiterada dos nomes figurando no definiens relativo à noção respectiva por seus respectivos definiens, até que finalmente se chegue ao nome cuja atribuição ao analisandum se trata de demonstrar. Uma demonstração se consumará, assim, em uma proposição idêntica, isto é, uma proposição em que o termo que ocupa a posição de predicado aparece também dentre aqueles em que o termo sujeito foi resolvido (Cf. GI \$38 (AA,VI, iv, p. 755). Ver também (1996) I, p. 194 e AA VI iii, 504). Ora, é esse procedimento que parece orientar aquele pelo qual se identifica, em dupla, o predicado que, integrando sua definição, encerra, por seu turno, em sua própria definição o predicado par.

19 Assim expostas as relações a serem demonstradas, pareceria que a única figura de silogismo adequada seria a primeira. De fato, Aristóteles estima ser esta a "mais científica" (Cf. ARISTÓTELES, 1980, Segundos Analíticos I 14, 79a17-18). As figuras restantes, desse ponto de vista, poderiam ser úteis para firmar crenças que não exibem as condições para serem consideradas como conhecimentos científicos, como é o caso da opinião $<\delta$ ó $\alpha>$, ou enquanto etapas intermediárias na investigação, que não reuniriam todas as condições para proporcionar uma demonstração.

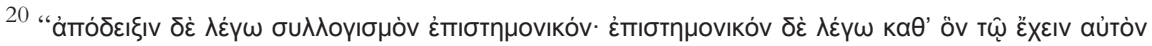

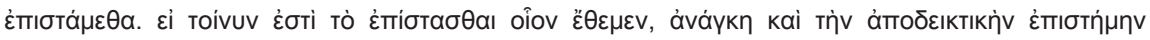

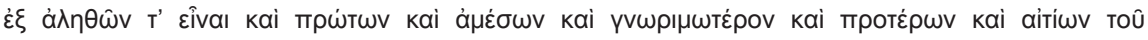

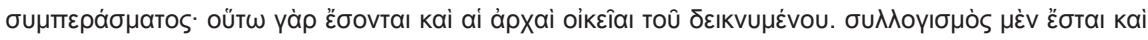

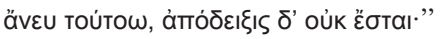

${ }^{21}$ Cf. Segundos Analíticos II, 11 (94a20-95a9).

22 Nesse capítulo, Aristóteles considera casos em que a aquisição dos conhecimentos observa uma ordem inversa àquela da explicação causal desses conhecimentos. Ele então contrasta exemplos de silogismos que proporcionam um mero conhecimento de que uma proposição é verdadeira com tipos de silogismos que proporcionam um conhecimento da causa ou razão para a verdade da proposição. Um exemplo elucidativo desse contraste reside na comparação do silogismo pelo qual, segundo ele, se conhece que a lua é esférica com o silogismo pelo qual se conhece por que a lua tem tais e tais fases (Cf. 78b4-13). No primeiro caso, temos, na posição de termo médio, a expressão o que possui tais fases. Como predicado desse termo na premissa temos esférico e, na posição de sujeito para esse termo temos lua. O silogismo deixa-se apresentar da seguinte maneira: Se esférico inere a o que possui tais fases, e se o que possui tais fases inere a lua, esférico inere a lua. Ora, pondera Aristóteles, não é porque a lua possui tais fases que é esférica, mas, antes, é a sua forma esférica que encerra a razão que explica por que ela que possui tais fases. Um silogismo do porquê com estes mesmos termos, então, se apresentaria colocando-se esférico na posição de termo médio e o que possui tais fases na posição de predicado desse termo. Teríamos então o seguinte: $S e$ o que possui tais fases inere a esférico, $e$ se esférico

doispontos, Curitiba, São Carlos, vol. 11, n. 2, p.47-67, outubro, 2014 
inere a lua, então o que possui tais fases inere a lua. Este silogismo exibiria um conhecimento causal da proposição a lua possui tais fases.

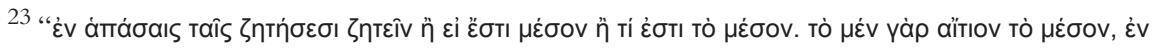

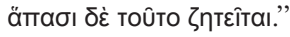

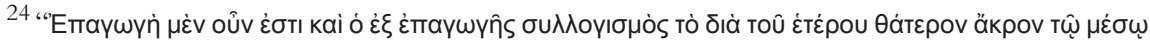

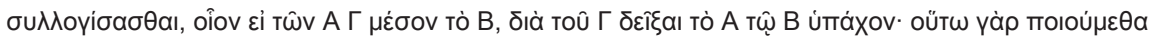
Tàs ह̇ாaүwyás."

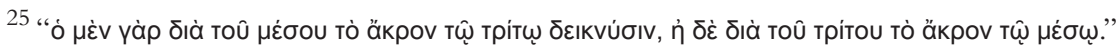

${ }^{26}$ Como dito, para Aristóteles, nem todo silogismo proporciona uma demonstração. Silogismos que não exibem os traços específicos da demonstração encontram-se na dialética, bem como na retórica (Cf. Primeiros Analíticos I 1, 24a22-b3; Tópicos. I 1, 100a27-b22; e Ret. I 2, 1356b5-6).

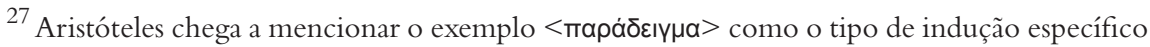
da retórica (Cf. ARISTÓTELES, 2008, I 2, 1356b5-6). Para uma discussão sobre as diferentes acepções ou espécies de indução em Aristóteles, verVON FRITZ, 1964, p. 54 e seg.

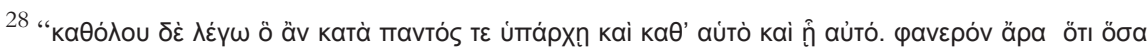

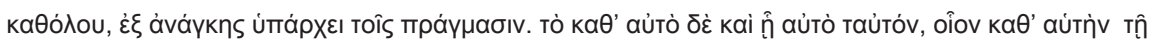

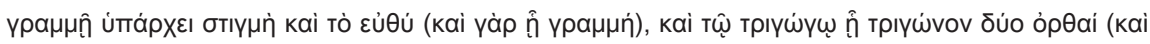

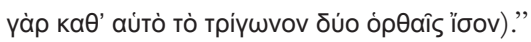

${ }^{29}$ Nos Segundos Analíticos I 4, Aristóteles distingue quatro acepções sob as quais emprega a expressão por si mesmo. Além das que serão abordadas aqui, ele considera que designamos por si mesmo aquele tipo de itens que não se atribuem a um sujeito deles distinto, isto é, as essências (73b5-8) e, em quarto lugar, afirma que consideramos ser atribuído por si mesmo a um sujeito um predicado implicado por um outro predicado atribuído ao mesmo sujeito (73b10-16).

30 “Inerem por si mesmos aqueles que integram o o que é, por exemplo, ao triângulo [inere] a linha, e à linha, o ponto (pois a essência dos primeiros resulta dos segundos, isto é, estes inerem ao discurso que enuncia o que aqueles são. Também inerem por si mesmos aqueles, dentre os que inerem a algo, se este algo inere ao discurso que explica o que são eles. Por exemplo, o reto inere à linha, assim como o curvo, e o par e o ímpar ao número. Pois, em todos estes, ora linha,

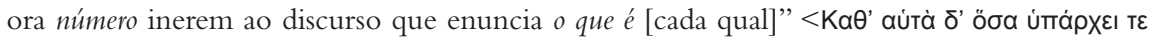

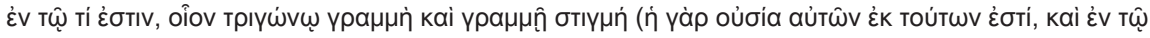

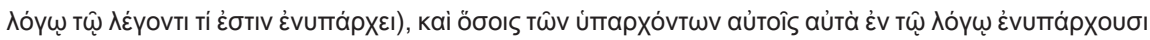

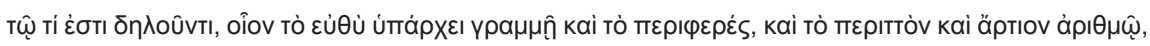

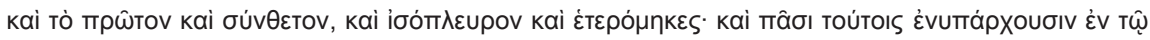

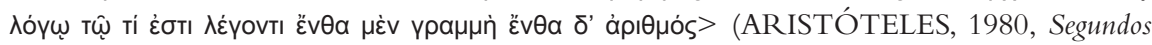
Analíticos I 4, 73a34-b3).

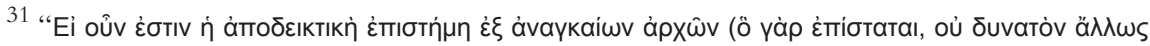
हैX

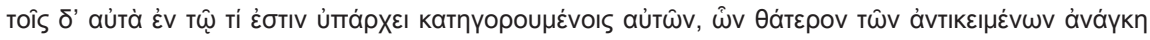

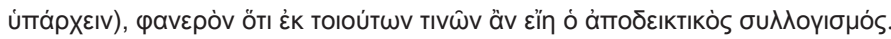

32 Parece dificil conciliar essa tese com ao menos duas outras sabidamente aristotélicas. Uma delas também figura nos Segundos Analíticos e expressa na recusa de que haja conhecimento

doispontos, Curitiba, São Carlos, vol. 11, n. 2, p.47-67, outubro, 2014 
científico do que é fruto do acaso (Cf. Segundos Analíticos I 30, 87b19-27). A outra consiste na tese de que não há definição de indivíduos (Cf. MetafísicaVII 10, 1036a2-8).

No que concerne a esta última tese, a dificuldade salta aos olhos: se a demonstração da atribuição de um predicado a um indivíduo depende da análise da definição deste último até que daí emerja o predicado a ser dele demonstrado, visto não haver definição de indivíduo, não é possível análise. Todas as demonstrações possíveis a respeito de um indivíduo lhe dizem respeito na medida em que ele se subsume sob uma definição (Cf. Metafísica Z 10,1036a2-8). A primeira tese, por seu turno, está intrinsecamente associada à dificuldade relativa à contingência.Visto que o acaso se define como uma espécie de contingente, a saber, aquele contingente que se admite poder indiferentemente ser ou não ser tal e tal, o que é por acaso parece corretamente descrito por uma verdade na qual o predicado atribuído não pode em absoluto ser admitido demonstrável a respeito do sujeito respectivo. Caso o fosse, esse sujeito não poderia indiferentemente encerrar ou não encerrar o predicado, mas deveria antes, encerrá-lo necessariamente.

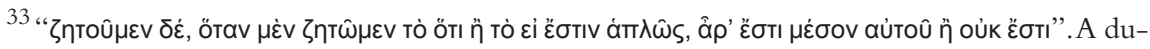

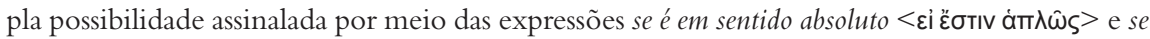
é [tal] < то̀ öті> reflete a distinção traçada por Aristóteles entre o que ele considera um tipo pri-

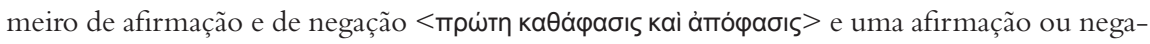
ção gramaticalmente mais complexa, em que o verbo ser é acrescentado a título de um terceiro item linguístico, articulando o que se comportará, então, como sujeito e como predicado no enunciado resultante (Cf. De Interpretatione 10, 19b14-22). Essas duas formas de enunciados proposicionais distinguidas por Aristóteles passaram a ser posteriormente conhecidas como proposições de segundo adjacente e proposições de terceiro adjacente respectivamente, terminologia de que Leibniz se serve para tratar das supraditas formas proposicionais. O que Aristóteles designa,

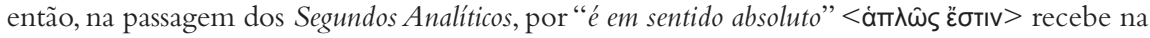
linguagem formalizada exposta por Leibniz em suas $G I$ a forma $A B$ é. O que, por seu turno, Aristóteles identifica no mesmo trecho de Segundos Analíticos como enunciando que é <öтı हैंTI> condensa a estrutura predicativa desdobrada de uma proposição de terceiro adjacente, para cuja formalização Leibniz emprega a expressão $A$ é B (Ver GI, \$144; ver também \$151).

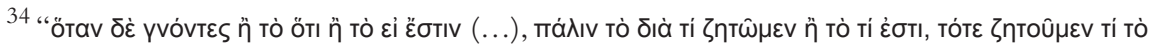

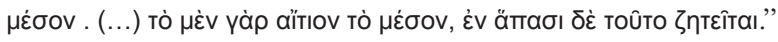

35 “тріа үà

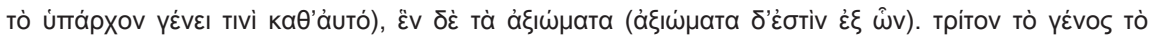

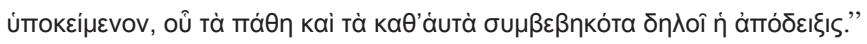

${ }^{36}$ Para uma discussão a respeito, ver ANGIONI, 2004.

\section{Referências bibliográficas}

ARISTÓTELES. 2008. Ars Retorica. Ross, D. (ed.). Oxford: OUP. 1988. Categoriae et Liber de Interpretatione. Minio-

Paluello, L. (ed.). Oxford: OUP.

doispontos, Curitiba, São Carlos, vol. 11, n. 2, p.47-67, outubro, 2014 
1997. Metaphysics.Vols. I e II. Ross, D. (ed.). Oxford:

Clarendon Press.

1989. Prior Analytics. Smith, R. (transl. and notes).

Indianápolis: Hackett Publishing Co.

1980. Prior and Posterior Analytics. Ross, D. (ed.). Oxford:

Clarendon Press.

. 2002. Topiques. Tomes I et II. Brunschwig J. (ed.). Paris:

Les Belles Lettres.

LEIBNIZ, G. W. 1996. Die Philosophischen Schriften. Gerhardt., I. (ed.). Hildesheim: George Olms Verlag.

2004. Discours de Métaphysique et Monadologie. Fichant,

M. (ed.). Paris: Gallimard.

1988. Opuscules et Fragments Inédits. Couturat. L. (ed.).

Hildesheim: George Olms Verlag.

(AA). Sämtliche Schriften und Briefe. Berlin: Deutschen

Akademie der Wissenschaften zu Berlin.

ANGIONI, L. 2004. Relações causais entre eventos na ciência

aristotélica. Em: Revista Analytica, Vol 8, nº 1, pp. 13-25.

APHRODISIAS, A. 1883. In Aristotelis Analyticorum Priorum Librum I

Commentarium. Wallies, M. Commentaria in Aristotelem Graeca,Vol. II -

P. I. Berolini:Typis et Impensis G. Reimeri.

VON FRITZ, K. 1964. Die epagôgê bei Aristoteles. München: Bayerischen Akademie der Wissenschaften.

HOBBES, T. 2009. Do Corpo - Parte I: Cálculo ou Lógica. Limongi, M. e Moreira,V. (trad.) São Paulo: Editora UNICAMP. 1999. De Corpore - Elementorum Philosophiae Sectio Prima.

Schumann, K. (ed.). Paris:Vrin.

ŁUKASIEWICZ, J. 1972. Aristotle's Syllogistic from the Standpoint of the Modern Formal Logic. Oxford: OUP. 
PARKINSON, G. 1965. Logic and Reality in Leibniz's Metaphysics. Oxford: OUP.

PATZIG, G. 1968. Aristotle's Theory of Syllogism. Barnes, J. (transl.). Dordrecht: D. Reidel Publishing Co.

RAUZY, J.-B. 2001. La docrtine leibnizienne de la vérité. Paris:Vrin. 